\title{
Positive parenting : protect children from the hazard of gadgets
}

\author{
Ika Sari Dewi ${ }^{1 *}$, Etti Rahmawati ${ }^{1}$, Dina Nazriani ${ }^{1}$, Amalia Meutia ${ }^{1}$, Suri Mutia Siregar ${ }^{1}$ \\ ${ }^{1}$ Departement of Psychology, Faculty of Psychology, Universitas Sumatra Utara \\ *Email: ikamikada@gmail.com
}

\begin{abstract}
Technological developments have colored every aspect of life in various age levels. The age group of children belongs to a group that is vulnerable to the development of these technologies, especially the use of gadgets. Rational and age-appropriate gadget usage is one way to overcome the impact of using gadgets. This community service program aims to provide information and skills on how to deal with or handle the use of gadgets for children. This program is carried out with the delivery of 4 (four) materials through lectures, focus group discussions, and role play. Four material presented are: introduction to children's growth and development, the impact of gadgets, how to recognize the behavior of children who are addicted to gadgets, and design activities to make children avoid gadgets. The results of data analysis of the tests before and after the implementation of the program showed information about child growth and development which contributed $21.66 \%$ in increasing parents 'and teachers' knowledge of their children's development, information about the dangers of gadgets contributed $40.75 \%$ in increasing the knowledge of parents and teachers, and information about positive parenting has a very significant role of $46.05 \%$ in increasing the knowledge of parents and teachers towards positive parenting.
\end{abstract}

Keyword: positive parenting, child development, gadget danger

\begin{abstract}
Abstrak
Perkembangan teknologi telah mewarnai setiap aspek kehidupan diberbagai tingkatan usia. Kelompok usia anak termasuk ke dalam kelompok yang rentan terhadap perkembangan teknologi tersebut, terutama penggunaan gadget. Penggunaan gadget yang rasional dan sesuai usia adalah salah satu cara untuk mengatasi dampak penggunaan gadget. Program pengabdian kepada masyarakat ini bertujuan untuk memberikan informasi dan keterampilan mengenai cara menghadapi atau menangani penggunaan gadget pada anak. Program ini dilaksanakan dengan penyampaian 4 (empat) materi melalui ceramah, focus group discussion, dan role play. Empat materi yang disampaikan yaitu : pengenalan tumbuh kembang anak, dampak dari gadget, cara mengenali perilaku anak yang kecanduan gadget, dan merancang aktivitas untuk membuat anak menghindari gadget. Hasil analisis data terhadap tes sebelum dan sesudah pelaksanaan program menunjukkan informasi tentang tumbuh kembang anak yang memberikan kontribusi sebesar 21,66\% dalam meningkatkan pengetahuan orang tua dan guru terhadap tumbuh kembang anak-anak mereka, informasi mengenai bahaya gadget memberikan sumbangan sebesar 40,75\% dalam meningkatkan pengetahuan para orang tua dan guru, dan informasi mengenai positive parenting memiliki peran yang sangat signifikan sebesar 46,05\% dalam meningkatkan pengetahuan para orang tua dan guru terhadap pola asuh orang tua yang positif.
\end{abstract}

Kata Kunci: positive parenting, tumbuh kembang anak, bahaya gadget

\section{PENDAHULUAN}

\subsection{Analisis Situasi}

Indonesia merupakan bangsa yang besar. Masa depan bangsa dan negara Indonesia ada di tangan generasi penerusnya. Generasi penerus bangsa terletak pada anak yang kemudian diharapkan tumbuh menjadi pemimpin yang memiliki karakter kuat untuk membangun bangsa dan negaranya, memiliki kepribadian unggul sebagai pemimpin, berjiwa nasionalis, memiliki pengetahuan mumpuni, dan memiliki penguasaan yang baik terhadap teknologi. Tuntutan ini untuk menghadapi persaingan global yang telah berlangsung. Selain itu, generasi 
penerus bangsa juga harus disadarkan akan peran dan pengaruh mereka yang sangat besar dalam proses perubahan sosial yang terjadi dan mereka juga memiliki peran sentral sebagai pengontrol terhadap arah perusabahan sosial ke arah yang lebih baik.

Keluarga memiliki peran sangat krusial untuk untuk mencetak generasi penerus yang memiliki kualitas seperti diharapkan. Keluarga merupakan lingkungan pendidikan pertama dimana anak-anak pertama sekali dan banyak mendapat pendidikan serta bimbingan di awalawal kehidupannya. Keluarga berperan sebagai peletak pengetahuan dasar etika dan norma dalam kehidupan seseorang. Sehingga pendidikan dalam keluarga dianggap menjadi dasar pondasi karakter dalam berprilaku dan bersikap dalam bermasyarakat. Sebagai pondasi dasar, pendidikan karakter harus ditanamkan sejak dini.

Akan tetapi dalam perkembangannya saat ini, usaha orang tua untuk memberikan pendidikan terbaik dalam keluarga memiliki tantangan tersendiri. Kemajuan teknologi yang tidak terbendung ditengah masyarakat membawa dampak tersendiri yang harus disikapi secara bijak dan positif. Salah satu dampak penggunaan teknologi yang saat ini mendapat sorotan adalah penggunaan gadget pada anak-anak. Banyak orang tua memberikan keleluasaan besar pada anak-anak mereka untuk menggunakan gadged dan tidak sedikit dari mereka telah membelikannya sejak usia dini. Para orang tua biasanya mengizinkan anak-anak mereka menggunakan gadged saat mereka sedang mengerjakan pekerjaan rumah atau hal lainnya dengan harapan anak-anak dapat tenang dan tidak mengganggu, menenangkan saat mereka terkesan rewel berada di tempat umum, atau para orang tua lebih senang anak-anak mereka bermain di rumah agar lebih mudah untuk diawasi. Meskipun tidak hanya menimbulkan dampak negatif namun banyak pro kontra terkait pemberian gadged pada anak-anak terutama sejak usia dini.

Penggunaan gadget yang tidak terawasi akan membawa dampak yang sangat buruk. Berbagai dampak yang mungkin ditimbulkan akibat penggunaan gadged yang tidak sehat pada anak diantaranya : mengganggu pertumbuhan otak, mengganggu tumbuh kembangnya (lamban dalam perkembangan motorik), gangguan kecemasan, agresif, radiasi emisi, dan perubahan perilaku yang signifikan. Memperhatikan dampak negatif yang ditimbulkan sangat berbahaya, menjadi sangat penting peran orang tua untuk mengawasi, mengontrol dan memperhatikan segala aktivitas anak saat menggunakan gadged. Karena benar-benar menjauhkan anak-anak dari gadget juga bukan jalan yang paling tepat, mengingat perannya juga besar dalam perkembangan zaman saat ini.

\subsection{Justifikasi Permasalahan}

Berdasarkan analisis yang telah dipaparkan di atas, permasalahan yang dihadapi oleh sasaran kegiatan ini dapat dijabarkan sebagai berikut :

1. Minimnya pengetahuan orang tua tentang tumbuh kembang anak.

2. Minimnya informasi yang terkait dengan dampak dari penggunaan gadget yang berlebihan dan yang tidak terkontrol.

3. Minimnya informasi mengenai manfaat dari positive parenting

\subsection{Tujuan Kegiatan}

Program pengabdian masyarakat bertajuk Positive Parenting : Lindungi Anak dari Bahaya Gadget bertujuan untuk :

1. Memberikan wawasan dan informasi tentang tumbuh kembang anak.

2. Memberikan wawasan dan informasi tentang penggunaan gadget yang berlebihan dan yang tidak terkontrol.

3. Memberikan wawasan dan informasi tentang positive parenting.

\subsection{Luaran Penelitian}

1. Peningkatan wawasan dan informasi orangtua mengenai tentang tumbuh kembang anak. 
2. Peningkatan wawasan dan informasi orangtua mengenai penggunaan gadget yang berlebihan dan yang tidak terkontrol.

3. Peningkatan wawasan dan informasi orangtua mengenai positive parenting

\section{METODE PELAKSANAAN}

Metode yang digunakan adalah ceramah, diskusi, dan praktik langsung yang dijabarkan sebagai berikut ;

Pertama, pelaksanaan kegiatan ini dimulai dengan menganalisis permasalahan terhadap situasi mitra. Berdasarkan hasil pengamatan, ditemukan bahwa sebagian besar orangtua belum memiliki pemahaman yang memadai mengenai tumbuh kembang anak, bahaya gadget, dan positive parenting. Selain itu, analisis juga dilakukan dengan menggunakan tes sebelum pelaksanaan kegiatan yang menampilkan skor awal orangtua sebelum pelaksanaan kegiatan.

Kedua, pemecahan masalah dilakukan dengan mengadakan ceramah, FGD, dan role play kepada orangtua mengenai tumbuh kembang anak, bahaya gadget, dan positive parenting. Program pengabdian dilaksanakan selama 2 hari dengan target sasaran sebanyak 23 peserta. Peserta program pengabdian adalah orangtua siswa di TK Kurnia Medan.

Ketiga, setelah program pengabdian selesai dilaksanakan, diharapkan para orangtua mengalami peningkatan wawasan dan informasi mengenai tumbuh kembang anak, bahaya gadget, dan positive parenting. Perubahan wawasan orangtua diukur menggunakan tes setelah pelaksanaan kegiatan.

\section{HASIL DAN PEMBAHASAN (RESULT AND DISCUSSION)}

Kegiatan dilaksanakan selama 2 hari, dengan rincian sebagai berikut :

\begin{tabular}{|c|l|l|}
\hline No. & Kegiatan & Sub Kegiatan \\
\hline 1. & Materi 1 : pengasuhan dan tumbuh kembang anak & $\begin{array}{l}\text { Melakukan ceramah mengenai } \\
\text { pengasuhan dan tumbuh } \\
\text { kembang anak }\end{array}$ \\
\hline 2. & Materi 2 : bahaya gadget pada anak & $\begin{array}{l}\text { Melakukan ceramah mengenai } \\
\text { bahaya gadget pada anak }\end{array}$ \\
\hline 3. & Mengenali kecanduan gadget pada anak & $\begin{array}{l}\text { Pelaksanaan Focus Group } \\
\text { Discussion mengenai gejala } \\
\text { kecanduan gadget pada anak }\end{array}$ \\
\hline 4. & Cara menangani kecanduan gadget & $\begin{array}{l}\text { Pelaksanaan Role Play } \\
\text { mengenai alternatif kegiatan } \\
\text { yang dapat digunakan untuk } \\
\text { menangani kecanduan gadget. }\end{array}$ \\
\hline
\end{tabular}

Kegiatan pengabdian "Positive Parenting : Lindungi dari Bahaya Gadget" dilakukan untuk meningkatkan pengetahuan mitra dan masyarakat sekitar mitra mengenai dampak positif dan negatif gadget pada anak. Untuk mendapatkan data mengenai hal tersebut kami memberikan tes sebelum dan sesudah pelaksanaan program. Tes dibuat sendiri oleh tim pengabdian berdasarkan kerangka pelaksanaan program pengabdian. Setiap peserta dalam program pengabdian memiliki 2 kali kesempatan untuk mengerjakan tes. Data dari peserta program pengabdian disajikan pada lampiran 1. Hasil analisis deskriptif disajikan pada tabel 1.

Tabel 1. Hasil Analisis Deskriptif.

\begin{tabular}{|l|l|l|l|}
\hline Variabel & \multicolumn{1}{|c|}{ Tes } & \multicolumn{1}{|c|}{ Rerata } & N \\
\hline \multirow{2}{*}{ Tumbuh Kembang } & Pre & 46.43 & 14.00 \\
\cline { 2 - 5 } & Post & 60.71 & 14.00 \\
\hline \multirow{2}{*}{ Gadget } & Pre & 42.86 & 14.00 \\
\cline { 2 - 5 } & Post & 66.67 & 14.00 \\
\hline
\end{tabular}


Ika Sari Dewi,et.al. Positive parenting : protect children

\begin{tabular}{|l|l|l|l|}
\hline \multirow{2}{*}{ Positif Parenting } & Pre & 46.43 & 14.00 \\
\cline { 2 - 4 } & Post & 69.05 & 14.00 \\
\hline
\end{tabular}

Keterangan : N : Jumlah Subjek

Berdasarkan hasil analisis diketahui bahwa rata-rata nilai pengetahuan tentang tumbuh kembang anak yang dimiliki oleh para orang tua dan guru sebelum diberikan informasi adalah sebesar 46.43 dan menjadi 60.71 setelah mendapatkan informasi. Berdasarkan nilai rerata dapat diketahui bahwa nilai rata-rata pengetahuan orang tua tentang tumbuh kembang pada anak meningkat. Variasi nilai pengetahuan tentang tumbuh kembang anak sebelum diberi informasi lebih kecil yaitu 18.70 dibandingkan setelah mendapatkan informasi sebesar 27.43. Hal ini menunjukkan bahwa terjadi perubahan pengetahuan disebagian besar responden. Demikian hal nya terjadi pada pengetahuan orang tua terhadap dampak negatif gadged bagi perkembangan anak. Terjadi perubahan besar pada pengetahuan orang tua dan juga guru tentang bahaya gadget pada anak, hal ini ditunjukkan dengan nilai rata-rata sebelum pemberian informasi sebesar 42.86 dengan variasi nilai sebesar 14.19 menjadi 66.67 dengan variasi nilai sebesar 26.95. Sedangkan nilai ratarata secara keseluruhan yang menunjukkan pengetahuan orang tua dan juga guru terhadap pola asuh positif parenting mengalami peningkatan sebelum dan sesudah mendapatkan informasi dari narasumber. Para orang tua dan juga guru memiliki pengetahuan yang lebih baik setelah diberikan informasi. Hal ini ditunjukkan dengan perubahan nilai rata-rata dari 46.43 dengan variasi nilai 18.70 menjadi 69.05 dengan variasi nilai 20.52.

Sebelum dilakukan analisis lebih lanjut menggunakan uji t untuk memastikan bahwa informasi yang diberikan benar-benar bermanfaat membantu orang tua dan para guru memiliki pengetahuan yang lebih baik tentang tumbuh kembang anak-anak mereka, bahaya penggunaan gadget terutama bagi anak-anak usia dini, dan juga pola pengasuhan positif maka dilakukan analisis prasyarat. Analisis distribusi normal sebelum melakukan uji t dilakukan menggunakan Shapiro-Wilk. Hasil analisis uji asumsi distribusi normal disajikan pada tabel 2.

Tabel 2. Hasil Uji Normalitas.

\begin{tabular}{|l|l|c|c|}
\hline \multirow{2}{*}{ Variabel } & \multicolumn{3}{c|}{ Shapiro-Wilk } \\
\cline { 2 - 4 } & Statistik & Db & P \\
\hline Tumbuh Kembang & 0,961 & 14 & 0,732 \\
\hline Bahaya Gadget & 0,900 & 14 & 0,111 \\
\hline Positive Parenting & 0,929 & 14 & 0,300 \\
\hline
\end{tabular}

Keterangan : Db : Derajat Bebas

$\mathrm{P}$ : Signifikansi

Berdasarkan hasil analisis yang disajikan pada tabel 2 diketahui bahwa distribusi selisih nilai pada saat pretes dan post tes memiliki distribusi mendekati distribusi normal ditunjukkan dengan nilai signifikansi (p) pada semua variabel lebih besar dari 0.05. Dengan demikian dapat dilakukan pengujian lebih lanjut menggunakan uji t. Hasil analisis dengan uji t disajikan pada tabel 3.

Tabel 3. Hasil Analisis Perbedaan Nilai Rata-Rata.

\begin{tabular}{|l|l|l|l|l|l|l|}
\hline Pre-Post & Rerata & \multicolumn{1}{c}{ Sd } & SEM & T & P & \multicolumn{1}{c|}{ SE } \\
\hline $\begin{array}{l}\text { Tumbuh } \\
\text { Kembang }\end{array}$ & -14.29 & 29.13 & 7.785 & -1.84 & 0,089 & 21,66 \\
\hline Bahaya Gadget & -23.81 & 29.75 & 7,950 & -2.99 & 0,010 & 40,75 \\
\hline $\begin{array}{l}\text { Positive } \\
\text { Parenting }\end{array}$ & -11.62 & 25.41 & 6,790 & $-3,331$ & 0,005 & 46,05 \\
\hline
\end{tabular}

Keterangan : SEM : Standard Error of Mean

SD : Standar Deviasi

$\mathrm{T}$ : Hasil uji beda 
P : Signifikansi

SE : Sumbangan Efektif

Berdasarkan hasil analisis diketahui bahwa meskipun terjadi peningkatan pengetahuan para orang tua dan guru tentang tumbuh kembang anak dengan selisih nilai rata-rata antara sebelum dan sesudah diberi informasi sebesar 14,29, namun perbedaan ini terjadi hanya secara kebetulan pada sampel yang dilibatkan dan tidak terjadi pada semua populasi yang mungkin. Hal ini ditunjukkan dengan nilai t sebesar 1,87 dan p sebesar 0.089. Informasi tentang tumbuh kembang anak yang diberikan memberikan kontribusi sebesar $21,66 \%$ dalam meningkatkan pengetahuan orang tua dan guru terhadap tumbuh kembang anak-anak mereka.

Sementara itu untuk pemberian informasi bahaya gadget, berdasarkan hasil analisis diketahui bahwa informasi yang diberikan memiliki sumbangan yang besar yaitu sekitar 40,75\% dalam meningkatkan pengetahuan para orang tua dan guru. Berdasarkan hasil uji beda nilai rata-rata sebelum diberi informasi dengan sesudah, diketahui terdapat perbedaan yang signifikan dengan selisih nilai rerata sebesar 23,81, nilai $\mathrm{t}=2.99$ dan $\mathrm{p}=0.01$.

Pada pengujian pengetahuan terhadap positif parenting diketahui terdapat perbedaan rerata yang sangat signifikan saat orang tua belum diberi informasi dengan sesudah diberi informasi, ditunjukkan dengan selisih rerata sebesar 11,62 dengan nilai t sebesar 3,331 dan p sebesar 0.005. Informasi yang disampaikan memiliki peran yang sangat signifikan sebesar $46,05 \%$ dalam meningkatkan pengetahuan para orang tua dan guru terhadap pola asuh orang tua yang positif.

\section{KESIMPULAN DAN SARAN}

\subsection{Kesimpulan}

Setelah dilakukan program pengabdian kepada masyarakat, ditemukan bahwa terjadi perbedaan skor sebelum dan sesudah orangtua mendapatkan informasi mengenai tumbuh kembang anak, bahaya gadget, dan positive parenting. Program pengabdian dilaksanakan dengan 3 metode, yaitu ceramah, focus group discussion, dan role play.

\subsection{Saran}

Peningkatan pengetahuan yang diperoleh oleh para partisipan dalam program pengabdian ini akan lebih afektif bila disertai dengan peningkatan atau pengembangan keterampilan partisipan agar dapat menjadi orangtua tangguh bagi anak dan keluarga dalam menghadapi derasnya arus teknologi informasi. Untuk itu disarankan agar program pengabdian masyarakat ini dilanjutkan secara berkesinambungan dengan memberikan program-program berikut ini :

a. Pelatihan komunikasi efektif.

b. Pengembangan kreativitas alternatif aktivitas "fun and educative for children".

c. Pelatihan cara menangani kecanduan gadge praktis untuk orangtua.

\section{UCAPAN TERIMAKASIH}

Ucapan Terima Kasih kepada Lembaga Pengabdian kepada Masyarakat Universitas Sumatera Utara yang telah Menfasilitasi Pelaksanaan Pengabdian Masyarakat IbM Mono Tahun (Dosen Muda)

\section{DAFTAR PUSTAKA (REFERENCES)}

Amoros, P., Balsells, M. À., Buisan, M., Byrne, S., \& Fuentes-Peláez, N. (2013). Im- plementation and Evaluation of the "Learning Together, Growing In Family Pro- gramme": The Impact On The Families. Revista de Cercetare si Interventie Sociala, 42, 120-144. 
Barlow, J., Smailagic, N., Huban, M., Roloff, V., \& Bennett, C. (2012). Parent-training programmes for improving parental psychosocial health. Campbell Systematic Reviews. The Campbell Collaboration.

Beltman, S., \& MacCallum, J. (2006). Mentoring and the development of resilience: An Australian perspective. The International Journal of Mental Health Promotion, 8(1), 21-32.

Masten, A. S. (2015). COURSERA: Resilience in Children Exposed to Trauma, Disaster and War: Global Perspectives. University of Minnesota.

O'Connor, T. G. (2002). Annotation: The "effects" of parenting reconsidered: findings, challenges, and applications. Journal of Child Psychology and Psychiatry, and Allied Disciplines, 43(5), $555-572$.

Shaw, D. S., Dishion, T. J., Supplee, L., Gardner, F., \& Arnds, K. (2006). Randomized trial of a family-centered approach to the prevention of early conduct problems: 2- year effects of the family check-up in early childhood. Journal of Consulting and Clinical Psychology, 74(1), 19.

Small, S. A., Cooney, S. M., \& O'Connor, C. (2009). Evidence-Informed Program Improvement: Using Principles of Effectiveness to Enhance the Quality and Impact of Family-Based Prevention Programs. Family Relations, 58(1), 1-13.

Whittaker, K. a., \& Cowley, S. (2012). An effective programme is not enough: a review of factors associated with poor attendance and engagement with parenting support programmes. Children \& Society, 26(2), 138-149. 